\title{
Análise dos impactos socioeconômicos na economia brasileira em 2015 e 2016 decorrentes da desvalorização do Real em relação ao Dólar
}

\author{
Gabriel M. Domingues*, Marcelo P. da Cunha
}

\begin{abstract}
Resumo
Com o objetivo de avaliar quantitativamente o impacto geral que a desvalorização do Real frente ao Dólar ocorrida entre 2014 e 2015 teve na economia brasileira, não apenas considerando o efeito positivo na balança comercial decorrente dessa desvalorização, foi realizado um estudo com base na estrutura da economia brasileira e utilizando um modelo baseado na Análise de Equilíbrio Geral, avaliando os efeitos dessa devsalorização na economia em termos das mudanças nos preços relativos, bem como as alterações no comportamento do consumo, do setor produtivo e do investimento durante a recessão de 2015 e 2016. Observou-se que, havendo ou não recessão, a desvalorização cambial apresenta um impacto negativo na economia, tendo seu impacto no PIB sido negativo $(0,34$ pontos percentuais pior com a desvalorização), também intensificando ainda mais a queda no consumo das famílias (queda total de $8,91 \%$ ), bem como o aumento do desemprego (que aumentou em 17,65\%). O investimento apresenta queda de 5,34\%, e, no caso dos preços relativos, há uma pressão de aumento em torno de $16 \%$ dos preços gerais relativos ao preço do fator trabalho (salários).
\end{abstract}

\section{Palavras-chave:}

Desvalorização do Real, Crescimento Econômico, Análise de Equilíbrio Geral

\section{Introdução}

Com a queda da atividade econômica (recessão) de 2015 e 2016, pôde-se observar a deterioração de diversas variáveis econômicas. O PIB, calculado sob a ótica da demanda, inclui o Consumo das Famílias, em queda devido ao crescente desemprego no período; o Gasto do Governo, que devido ao déficit nas contas públicas estava incapacitado de crescer buscando impulsionar o crescimento; o Investimento, que tendia somente a cair dada a elevada capacidade ociosa da economia no período; e a Balança Comercial, a única positivamente estimulada devido, majoritariamente, à desvalorização cambial no período. Sabe-se que a Balança Comercial foi positiva, auxiliando contra a recessão no período, mas faz-se necessário avaliar se a mesma Desvalorização Cambial que impulsionou a Balança Comercial teria, considerando todos os seus outros impactos nos preços relativos e na economia, causado impactos negativos ou positivos, no geral bem como em variáveis específicas, e como isso ocorreu.

\section{Resultados e Discussão}

Foram realizados dois choques distintos, e também um terceiro choque dos dois anteriores conjuntamente. $O$ primeiro, o choque Redução da Oferta do Fator Capital, foi realizado para simular a recessão econômica, causando uma queda de $7,35 \%$ do PIB (simulando a queda acumulada de 2015 e 2016). O segundo choque foi na taxa de câmbio, desvalorizando-a em 20\%. Na avaliação dos choques conjuntamente, o PIB caiu ainda mais do que apenas na modelagem da Recessão, mostrando que a Desvalorização Cambial não estimulou o Crescimento Econômico, apesar de ter sim melhorado - saldo da Balança Comercial. Os preços relativos apresentaram elevado aumento em relação ao preço do Fator Trabalho (16\%), uma vez que o aumento do desemprego causado foi de $17,65 \%$, intensificado pela desvalorização cambial, o que causa redução no preço do fator trabalho (salário), sendo natural o aumento dos outros preços da economia frente a ele (mantido constante como referencial no modelo). O investimento, que considerando somente a recessão teria subido devido ao aumento das poupanças, apresentou queda no efeito Choque Conjunto, isto é, a Desvalorização Cambial contraiu o Investimento, num efeito acumulado de 5,34\%. Com os resultados observados, podemos concluir que a Desvalorização Cambial não apresentou melhora em nenhuma das variáveis agregadas de análise utilizadas, piorando crescimento do produto, o desemprego, o consumo das famílias e o investimento. A metodologia da Análise de Equilíbrio Geral se mostra muito eficiente na Análise dos efeitos macroeconômicos dessas mudanças dada a estrutura da economia brasileira, considerando as mudanças nos preços relativos e comportamento dos agentes.

\section{Conclusões}

Como foi discutido anteriormente, uma Desvalorização do Real Frente ao Dólar como a ocorrida em 2014, analisada ambos isolada e conjunatemente com a modelagem do cenário recessivo, impactou todas as variáveis econômicas analisadas negativamente. Apesar de ter melhorado muito o saldo a Balança Comercial, isso não se mostrou suficiente para gerar crescimento ou qualquer melhora na economia. Isso contribui para o debate que se iniciou com relação à recessão de 2015 e 2016, referente a proposições de possíveis saídas para a crise. Podemos concluir que a Desvalorização Cambial não deveria, com base nos resultados encontrados, ser utilizada dessa forma como política econômica.

\section{Agradecimentos}

Agradecemos ao CNPq pelo financiamento da bolsa de Iniciação Científica que contribuiu para viabilizar esta pesquisa

VEREDA, L., CAVAlCANTI, M. A. F. H. Modelo Dinâmico Estocástico de Equilíbrio Geral (DSGE) para a economia brasileira: versão 1. Texto para Discussão (TD) 1479 - IPEA. Brasília, Março, 2010.

DE PAULA, L. F.; MANOEL, P. Crise e perspectivas para a economia brasileira. São Paulo: Estud. av. vol.31 no.89 Jan./Apr. 2017. 